\title{
Predictive Value of Remnant-like Particle Cholesterol as an Indicator of Coronary Artery Stenosis in Patients with Normal Serum Triglyceride Levels
}

\author{
Hiroshi Masuoka, Shigeru Kamei, Morihiro Ozaki, Atsushi Kawasaki, Uichiro Shintani, \\ MASAAKI ITO* and Takeshi NAKANO*
}

\begin{abstract}
Objective We designed the present study to evaluate the association of various lipid and fibrinolytic components with coronary artery stenosis with respect to the triglyceride (TG) level.

Methods Levels of TG, remnant-like particle cholesterol (RLP-C), total cholesterol, high-density lipoprotein cholesterol (HDL-C), low-density lipoprotein cholesterol (LDL-C), lipoprotein-(a), uric acid, blood glucose, tissue plasminogen activator (t-PA), t-PA inhibitor type 1, antithrombin III, and protein $C$ were measured in 208 patients who underwent diagnostic coronary angiograms.

Patients Of these 208 patients, 59 were hypertriglyceridemic (150 $\mathrm{mg} / \mathrm{dl}$ or higher) and 149 were normotriglyceridemic.

Results Both LDL-C and HDL-C showed significant differences between patients with and those without coronary artery stenosis in both hypertriglyceridemic and normotriglyceridemic patient subgroups. However, RLP$C$ showed a significant difference in the normotriglyceridemic patient subgroup $(p=0.012)$ but not in the hypertriglyceridemic patient subgroup $(p=0.736)$.

Conclusion Our current retrospective study disclosed that RLP-C levels are closely associated with coronary artery stenosis in patients with normal TG levels.

(Internal Medicine 39: 540-546, 2000)
\end{abstract}

Key words: RLP-C, coronary risk factor, hypertriglyceridemia, normotriglyceridemia

\section{Introduction}

Hypercholesterolemia has been recognized as a risk factor for coronary artery disease $(1,2)$. The risk for atherosclerotic coronary artery disease is directly correlated with low-density lipoprotein cholesterol (LDL-C) level (3). However, the triglyceride (TG) concentration alone is not always a good marker of the atherogenic potential $(4,5)$. In fact, the incidence of coronary artery disease in patients with familial hypertriglyceridemia has been reported to be relatively low (6). TG concentration has been considered to be a more efficient marker for coronary artery disease in certain patient subgroups as compared with others (7). One limitation of using plasma TG concentration as a predictor for coronary artery disease is that it does not separate the less atherogenic TG-rich lipoproteins, such as chylomicrons and nascent very-low-density lipoproteins (VLDL) (8), from their potentially more atherogenic components, such as VLDL remnants. Unfortunately, limited information is available for clinical use as to which factor has an additional discriminating power for isolating coronary artery disease patients in combination with the TG level. Such being the case, we designed the current study to compare the association of various lipid and fibrinolytic components with coronary artery stenosis between hypertriglyceridemic and normotriglyceridemic subjects. We also evaluated the levels of remnant-like particle cholesterol (RLP-C). RLP-C is a recently established simple assay method that estimates at least a part of serum triglyceride-rich lipoprotein remnants (9).

\section{Methods}

The study population was composed of 300 consecutive patients who underwent diagnostic coronary angiograms for possible coronary artery diseases. Data from repeated angiograms for the same patient were excluded. Patients who had liver disease, renal disease, endocrinologic disorders, neoplasm, and acute inflammatory disease were excluded. Patients who had had acute myocardial infarction within the past 1 month were also excluded. Of the remaining patients, the study

From the Division of Cardiology, National Mie Central Hospital, Hisai and *the First Department of Internal Medicine, Mie University School of Medicine, Tsu

Received for publication: August 13, 1999; Accepted for publication: January 31, 2000

Reprint requests should be addressed to Dr. Hiroshi Masuoka, the Division of Cardiology, National Mie Central Hospital, 2158-5 Myoujincho, Hisai, Mie 5141101 
population was limited to 208 patients. Written informed consent was obtained from each of these 208 patients before the study. The study protocol was approved by the Ethics Committee of our hospital.

Coronary angiogram was carried out mainly through the percutaneous brachial approach and occasionally through the femoral approach using the standard Judkin's technique. At least 5 views of the left coronary artery and 3 of the right were obtained. Computer-assisted quantitative coronary angiography was carried out in all patients using a cardiovascular angiography analysis system $(10,11)$. According to the reporting system of the American Heart Association (12), narrowing of greater than $51 \%$ stenosis was considered significant.

A venous blood sample was taken with minimal venostasis from an antecubital vein for the determination of each factor as follows: total cholesterol (automated enzymatic methods), high-density lipoprotein cholesterol (HDL-C; selective inhibition assay), LDL-C [Friedewald's equation (13) : LDL-C = total cholesterol - HDL-C - TG/5], TG (automated enzymatic methods), lipoprotein-(a) [Lp(a); latex immunoassay with a rabbit monoclonal anti-human $L p(a)$ antibody. This method is based on the latex-enhanced particle agglutination technology. A more detailed characterization has been given elsewhere (14)], RLP-C (immunoadsorption assay using mouse monoclonal anti-human apo B-100 and anti-human apo A-I immunoaffinity mixed gels. Briefly, the standard assay contains $5 \mu \mathrm{l}$ of serum and $50 \mu \mathrm{l}$ of mixed gel, which adsorbs lipoproteins containing apo A-I as well as most of the lipoproteins containing apo B-100. After 60 minutes of gentle shaking, unbound cholesterol present in the supernatant are measured enzymatically.), as well as uric acid (automated enzymatic methods), blood glucose (automated enzymatic methods), tissue plasminogen activator antigen [t-PA; enzyme-linked immunosorbent assay using monoclonal antibodies (15)], and t-PA inhibitor type 1 antigen [PAI-1; enzyme-linked immunosorbent assay (16). This procedure measured the total quantity of PAI-1 present, free or complexed with t-PA and in active or in inactive form], antithrombin III activity (AT III; chromogenic substrate assay), protein $\mathrm{C}$ activity (latex photometric immunoassay). Venous blood samples were collected before the catheterization and after the subjects had fasted for 12 hours. All lipid-lowering drugs were withdrawn $>7$ days before the study. The calculated values of LDL-C in 3 subjects with TG levels of $>400 \mathrm{mg} / \mathrm{dl}$ were excluded from the analyses concerning LDL-C.

The 4 conventional coronary risk factors were determined in each patient as follows: hypertension (systolic pressure $>160$ $\mathrm{mmHg}$ or diastolic pressure $>95 \mathrm{mmHg}$, or a satisfactory prior diagnosis), smoking habit (current smoker or former smoker with $>10$ cigarettes per day), diabetes mellitus (overt diabetes necessitating treatment or abnormal oral glucose tolerance test), obesity [body mass index (BMI) $>26$ ]. Each variable was examined when each patient underwent coronary angiogram. Blood pressure (BP) was measured by nurses in a standardized clinical setting with a mercury sphygmomanometer in the supine position after at least 10 minutes of rest. BP measure- ments were repeated at least three times in a blind fashion, and the mean values of repeated measurements represented the BP value. BMI was calculated from weight $(\mathrm{kg})$ divided by height (m) squared.

For statistical analysis, Student's unpaired 2-tailed $t$ test was used for comparisons between two groups. Mann-Whitney's $U$ test was performed if data sets were not normally distributed. Discrete data were analyzed by use of the chi-square test. A $p$ value of less than 0.05 was considered significant in each test. Multivariate logistic regression analysis was performed to determine the association of each parameter. It remains undetermined whether RLP-C is an independent covariate in relation to the various lipid and fibrinolytic variables. Thus, multivariate statistical analyses were carried out to assess the independent correlations between RLP-C level and levels of the other variables. Values of RLP-C, TG, Lp(a), glucose, $t$ $\mathrm{PA}$, and PAI-1 were transformed into natural logarithms in these multivariate statistical analyses.

\section{Results}

\section{Patient characteristics}

The mean age of the 208 patients studied was $63.8 \pm 8.7$ years (mean \pm SD) and ranged from 39 to 83 years. There were 149 males and 59 females. Of the patients, 56 (26.9\%) had no significant coronary artery stenosis or occlusion, whereas 152 (73.1\%) had significant organic stenosis. We defined the former 56 cases as group $\mathrm{N}$ (the group of patients who had no stenosis) and the latter 152 cases as group $S$ (the group of patients who had at least one stenosis or occlusion). The number of patients found to have 1-, 2-, or 3-vessel and left main disease in group $S$ was $71,47,25$, and 9, respectively. Patient characteristics were compared between group $\mathrm{S}$ and group $\mathrm{N}$, as shown in Table 1. The mean age and male-female ratio were higher in group $\mathrm{S}$. No significant differences were observed in the prevalence of conventional risk factors between groups $\mathrm{S}$ and $\mathrm{N}$.

The clinical diagnoses confirmed following coronary angiography were as follows: myocardial infarction in 61 cases,

Table 1. Comparison of Baseline Characteristics between Patients with (Group S) and Those without (Group N) Angiographically Determined Coronary Artery Stenosis

\begin{tabular}{llll}
\hline & $\begin{array}{l}\text { Group S } \\
(\mathrm{n}=152)\end{array}$ & $\begin{array}{l}\text { Group N } \\
(\mathrm{n}=56)\end{array}$ & Test for trend \\
\hline Age (yr) & $64.8 \pm 8.1$ & $61.0 \pm 9.8$ & $\mathrm{p}=0.021$ \\
Male gender (\%) & 74.3 & 64.3 & $\mathrm{p}=0.040$ \\
$\begin{array}{l}\text { Coronary risk factors }(\%) \\
\text { Hypertension }\end{array}$ & 44.1 & 41.1 & $\mathrm{NS}$ \\
$\begin{array}{l}\text { Diabetes mellitus } \\
\text { Smoking }\end{array}$ & 23.7 & 19.6 & $\mathrm{NS}$ \\
Obesity & 49.3 & 42.9 & $\mathrm{NS}$ \\
& 21.7 & 25.0 & $\mathrm{NS}$ \\
\hline
\end{tabular}

Data presented are mean \pm SD or percent of patients. NS: not statistically significant. 
angina pectoris in 97 cases, silent myocardial ischemia in 7 cases, positive stress test in 18 cases, neurocirculatory asthenia in 21 cases, cardiomyopathy in 2 cases, aortic disease in 2 cases.

\section{Monovariate analysis}

Mean levels of lipid and fibrinolytic components in group $S$ and group $\mathrm{N}$ of the total patients studied are presented in Table 2. HDL-C was significantly lower in Group S. LDL-C, TG, and RLP-C were significantly higher in group S. Protein C tended to be lower in group $\mathrm{S}$ but the difference did not reach statistical significance.

We divided the patients into 2 subgroups according to the TG levels. Patients with a TG level of $150 \mathrm{mg} / \mathrm{dl}(1.69 \mathrm{mmol} /$ 1) or higher were classified as the hypertriglyceridemic subgroup; 59 of the patients fell into this category. Patients with values lower than $150 \mathrm{mg} / \mathrm{dl}$ were classified as the normotriglyceridemic subgroup. This subgroup consisted of 149 patients. The two subgroups were similar with respect to clinical characteristics. Levels of TG, HDL-C, and RLP-C showed highly significant differences between normotriglyceridemic and hypertriglyceridemic patient subgroups, as shown in Table 3. Levels of total cholesterol, t-PA, glucose, BMI, and diastolic BP also reached significant differences between normotriglyceridemic and hypertriglyceridemic patient subgroups (Table 3).

We investigated whether differences exist in the association

Table 2. Comparison of the Lipid and Fibrinolytic Parameters between Patients with (Group S) and Those without (Group N) Angiographically Determined Coronary Artery Stenosis

\begin{tabular}{lccl}
\hline & Group S & Group N & $p$ Value \\
\hline T. Chol.(mg/dl) & $200.7 \pm 35.2$ & $188.2 \pm 31.4$ & 0.082 \\
LDL-C $(\mathrm{mg} / \mathrm{dl})$ & $133.3 \pm 35.9$ & $113.7 \pm 31.6$ & 0.010 \\
HDL-C $(\mathrm{mg} / \mathrm{dl})$ & $38.09 \pm 10.98$ & $52.63 \pm 13.58$ & 0.002 \\
TG $(\mathrm{mg} / \mathrm{dl})$ & $145.2 \pm 66.4$ & $107.6 \pm 43.4$ & 0.011 \\
Lp $(\mathrm{a})(\mathrm{mg} / \mathrm{dl})$ & $24.78 \pm 22.05$ & $21.14 \pm 18.89$ & 0.136 \\
RLP-C $(\mathrm{mg} / \mathrm{dl})$ & $6.84 \pm 5.63$ & $3.84 \pm 2.57$ & 0.0004 \\
uric acid $(\mathrm{mg} / \mathrm{dl})$ & $5.93 \pm 1.57$ & $5.34 \pm 1.88$ & 0.092 \\
glucose $(\mathrm{mg} / \mathrm{dl})$ & $115.2 \pm 36.1$ & $99.9 \pm 23.3$ & 0.085 \\
t-PA $(\mathrm{ng} / \mathrm{ml})$ & $10.05 \pm 4.60$ & $8.91 \pm 4.59$ & 0.077 \\
PAI-1 $(\mathrm{ng} / \mathrm{ml})$ & $32.93 \pm 27.67$ & $31.57 \pm 24.36$ & 0.625 \\
AT III $(\%)$ & $95.90 \pm 14.17$ & $98.13 \pm 13.50$ & 0.364 \\
protein C $(\%)$ & $98.20 \pm 21.82$ & $106.22 \pm 22.35$ & 0.060 \\
BMI $\left(\mathrm{kg} / \mathrm{m}^{2}\right)$ & $24.5 \pm 3.2$ & $23.6 \pm 3.8$ & 0.189 \\
systolic BP $(\mathrm{mmHg})$ & $121.9 \pm 15.8$ & $122.5 \pm 17.0$ & 0.861 \\
diastolic BP $(\mathrm{mmHg})$ & $70.6 \pm 9.8$ & $70.8 \pm 10.6$ & 0.911 \\
\hline
\end{tabular}

Data presented are mean \pm SD. T. Chol.: total cholesterol, LDL-C: lowdensity lipoprotein cholesterol, HDL-C: high-density lipoprotein cholesterol, TG: triglyceride, Lp(a): lipoprotein-(a), RLP-C: remnantlike particle cholesterol, t-PA: tissue plasminogen activator, PAI-1: tPA inhibitor type 1, AT III: antithrombin III, BMI: body mass index, BP: blood pressure. of the levels of various factors with coronary artery stenosis between hypertriglyceridemic and normotriglyceridemic patient subgroups. The mean levels of the various variables in groups $\mathrm{S}$ and $\mathrm{N}$ of the hypertriglyceridemic patient subgroup are presented in Table 4; those of the normotriglyceridemic patient subgroup are presented in Table 5. An appropriate $p$

Table 3. Comparison of the Lipid and Fibrinolytic Parameters between Normotriglyceridemic and Hypertriglyceridemic Patient Subgroups

\begin{tabular}{lccc}
\hline & Normo-TG & Hyper-TG & $p$ Value \\
\hline T. Chol. $(\mathrm{mg} / \mathrm{dl})$ & $193.1 \pm 31.9$ & $206.9 \pm 39.1$ & 0.045 \\
LDL-C (mg/dl) & $127.3 \pm 33.0$ & $127.9 \pm 42.3$ & 0.935 \\
HDL-C (mg/dl) & $45.27 \pm 14.13$ & $36.47 \pm 12.43$ & 0.002 \\
TG (mg/dl) & $102.9 \pm 27.3$ & $212.8 \pm 58.1$ & $<0.0001$ \\
Lp (a) (mg/dl) & $23.40 \pm 21.11$ & $18.88 \pm 16.12$ & 0.261 \\
RLP-C (mg/dl) & $4.94 \pm 4.77$ & $9.01 \pm 5.25$ & $<0.0001$ \\
uric acid (mg/dl) & $5.61 \pm 1.62$ & $6.14 \pm 1.79$ & 0.113 \\
glucose (mg/dl) & $103.7 \pm 28.7$ & $121.9 \pm 37.7$ & 0.024 \\
t-PA $(\mathrm{ng} / \mathrm{ml})$ & $9.08 \pm 4.21$ & $11.86 \pm 5.48$ & 0.013 \\
PAI-1 $(\mathrm{ng} / \mathrm{ml})$ & $30.39 \pm 24.35$ & $38.70 \pm 34.40$ & 0.134 \\
AT III $(\%)$ & $99.43 \pm 15.02$ & $97.06 \pm 13.85$ & 0.830 \\
protein C (\%) & $99.63 \pm 23.04$ & $102.34 \pm 21.92$ & 0.551 \\
BMI $\left(\mathrm{kg} / \mathrm{m}^{2}\right)$ & $23.6 \pm 3.3$ & $25.1 \pm 3.5$ & 0.033 \\
systolic BP $(\mathrm{mmHg})$ & $120.9 \pm 16.2$ & $123.9 \pm 16.1$ & 0.366 \\
diastolic BP $(\mathrm{mmHg})$ & $68.9 \pm 10.1$ & $73.2 \pm 9.6$ & 0.035 \\
\hline
\end{tabular}

Data presented are mean \pm SD. Normo-TG: normotriglyceridemic patient subgroup, Hyper-TG: hypertriglyceridemic patient subgroup. Other abbreviations as in Table 2.

Table 4. Comparison of the Lipid and Fibrinolytic Parameters between Patients with (Group S) and Those without (Group N) Angiographically Determined Coronary Artery Stenosis Assessed in the Hypertriglyceridemic Patient Subgroup

\begin{tabular}{lccc}
\hline & Group S & Group N & $p$ Value \\
\hline T. Chol.(mg/dl) & $210.4 \pm 38.2$ & $180.0 \pm 40.4$ & 0.130 \\
LDL-C (mg/dl) & $132.7 \pm 40.5$ & $90.7 \pm 41.6$ & 0.038 \\
HDL-C (mg/dl) & $34.65 \pm 11.63$ & $50.65 \pm 9.81$ & 0.010 \\
TG $(\mathrm{mg} / \mathrm{dl})$ & $215.3 \pm 60.0$ & $193.5 \pm 41.0$ & 0.404 \\
Lp $(\mathrm{a})(\mathrm{mg} / \mathrm{dl})$ & $19.80 \pm 16.49$ & $12.00 \pm 12.57$ & 0.273 \\
RLP-C $(\mathrm{mg} / \mathrm{dl})$ & $9.15 \pm 5.49$ & $7.98 \pm 3.12$ & 0.736 \\
uric acid $(\mathrm{mg} / \mathrm{dl})$ & $6.37 \pm 1.73$ & $4.30 \pm 1.28$ & 0.039 \\
glucose $(\mathrm{mg} / \mathrm{dl})$ & $122.5 \pm 38.7$ & $118.8 \pm 36.4$ & 0.743 \\
t-PA $(\mathrm{ng} / \mathrm{ml})$ & $11.40 \pm 5.17$ & $13.48 \pm 7.28$ & 0.223 \\
PAI-1 $(\mathrm{ng} / \mathrm{ml})$ & $37.23 \pm 32.42$ & $40.10 \pm 42.06$ & 0.489 \\
AT III $(\%)$ & $96.74 \pm 14.63$ & $99.50 \pm 8.20$ & 0.714 \\
protein C $(\%)$ & $101.68 \pm 22.74$ & $107.50 \pm 15.26$ & 0.624 \\
BMI $\left(\mathrm{kg} / \mathrm{m}{ }^{2}\right)$ & $25.4 \pm 3.6$ & $24.3 \pm 3.2$ & 0.366 \\
systolic BP $(\mathrm{mmHg})$ & $123.3 \pm 15.1$ & $125.1 \pm 18.1$ & 0.647 \\
diastolic BP $(\mathrm{mmHg})$ & $73.1 \pm 10.4$ & $73.1 \pm 9.5$ & 0.993 \\
\hline
\end{tabular}

Data presented are mean \pm SD. Abbreviations as in Table 2. 
Table 5. Comparison of the Lipid and Fibrinolytic Parameters between Patients with (Group S) and Those without (Group N) Angiographically Determined Coronary Artery Stenosis Assessed in the Normotriglyceridemic Patient Subgroup

\begin{tabular}{lccl}
\hline & Group S & Group N & $p$ Value \\
\hline T. Chol.(mg/dl) & $195.4 \pm 32.5$ & $189.2 \pm 30.8$ & 0.396 \\
LDL-C (mg/dl) & $133.7 \pm 33.4$ & $116.4 \pm 29.8$ & 0.033 \\
HDL-C (mg/dl) & $40.50 \pm 11.23$ & $53.35 \pm 15.01$ & $\varangle 0.0001$ \\
TG (mg/dl) & $106.3 \pm 24.9$ & $97.2 \pm 30.5$ & 0.162 \\
Lp (a) (mg/dl) & $22.75 \pm 20.08$ & $23.21 \pm 22.78$ & 0.721 \\
RLP-C (mg/dl) & $5.85 \pm 5.61$ & $3.39 \pm 2.18$ & 0.012 \\
uric acid (mg/dl) & $5.69 \pm 1.43$ & $5.47 \pm 1.91$ & 0.073 \\
glucose (mg/dl) & $108.7 \pm 32.9$ & $95.2 \pm 17.5$ & 0.047 \\
t-PA $(\mathrm{ng} / \mathrm{ml})$ & $9.46 \pm 4.29$ & $8.46 \pm 4.05$ & 0.207 \\
PAI-1 (ng/ml) & $31.36 \pm 26.14$ & $28.77 \pm 21.33$ & 0.632 \\
AT III (\%) & $95.16 \pm 15.04$ & $98.58 \pm 14.98$ & 0.303 \\
protein C (\%) & $93.98 \pm 20.78$ & $109.03 \pm 23.86$ & 0.003 \\
BMI $\left(\mathrm{kg} / \mathrm{m}^{2}\right)$ & $23.8 \pm 3.1$ & $23.3 \pm 4.2$ & 0.571 \\
systolic BP (mmHg) & $120.9 \pm 16.8$ & $120.7 \pm 16.0$ & 0.975 \\
diastolic BP (mmHg) & $68.1 \pm 8.9$ & $69.9 \pm 11.9$ & 0.523 \\
\hline
\end{tabular}

Data presented are mean \pm SD. Abbreviations as in Table 2.

value by unpaired two-tailed $t$ test or Mann-Whitney's $U$ test is presented for each variable. Both LDL-C and HDL-C levels were significantly different between groups $\mathrm{S}$ and $\mathrm{N}$ in the overall population (Table 2), in the hypertriglyceridemic patient subgroup (Table 4), and in the normotriglyceridemic patient subgroup (Table 5). While the RLP-C level was not significantly different in the hypertriglyceridemic patient subgroup (Table $4, p=0.736$ ), it was significantly different in the normotriglyceridemic patient subgroup (Table 5, $\mathrm{p}=0.012$ ). The protein $C$ level showed a significant difference between groups $\mathrm{S}$ and $\mathrm{N}$ only in the normotriglyceridemic patient subgroup. The uric acid level showed a significant difference only in the hypertriglyceridemic patient subgroup. These differences persisted after adjustment for age and gender between groups $\mathrm{S}$ and $\mathrm{N}$.

\section{Multivariate analysis}

Multivariate statistical analyses were carried out to assess the independent correlations between the RLP-C level and the levels of the other variables, as can be seen in Table 6 . The association of RLP-C level with the presence of coronary artery stenosis showed a marked difference between hypertriglyceridemic and normotriglyceridemic patient subgroups. Therefore, we evaluated whether the relationship among RLP-C and the other variables differed between hypertriglyceridemic and normotriglyceridemic patient subgroups. Multivariate analysis showed that the TG level was the only independent factor associated with RLP-C level when assessed in both overall patients and the hypertriglyceridemic patient subgroup. However, it showed that the levels of glucose and $\mathrm{Lp}(\mathrm{a})$ were independent factors associated with the RLP-C level
Table 6. Multivariate Statistical Analyses for Correlations of RLPC Level with Levels of Various Lipid and Fibrinolytic Parameters

\begin{tabular}{lrcrrrr}
\hline & \multicolumn{2}{c}{ Total patients } & \multicolumn{2}{c}{ Normo-TG } & \multicolumn{2}{c}{ Hyper-TG } \\
\hline \multicolumn{1}{c}{$\mathrm{r}^{2}$} & \multicolumn{2}{c}{0.489} & \multicolumn{2}{c}{0.587} & \multicolumn{2}{c}{0.557} \\
\hline & $\mathrm{b}$ & $p$ & $\mathrm{~b}$ & $p$ & $\mathrm{~b}$ & $p$ \\
\hline LDL-C & -0.041 & 0.701 & 0.259 & 0.079 & -0.136 & 0.522 \\
HDL-C & -0.110 & 0.362 & 0.125 & 0.434 & -0.160 & 0.557 \\
TG & 0.429 & 0.001 & 0.220 & 0.143 & 0.407 & 0.050 \\
Lp (a) & -0.106 & 0.295 & -0.385 & 0.015 & -0.042 & 0.841 \\
uric acid & 0.062 & 0.618 & 0.084 & 0.623 & 0.112 & 0.649 \\
glucose & 0.160 & 0.133 & 0.640 & 0.0001 & -0.044 & 0.831 \\
t-PA & 0.059 & 0.583 & -0.066 & 0.638 & 0.149 & 0.482 \\
PAI-1 & -0.046 & 0.648 & 0.035 & 0.808 & -0.021 & 0.923 \\
AT III & 0.133 & 0.223 & -0.036 & 0.795 & 0.380 & 0.091 \\
protein C & 0.180 & 0.109 & 0.117 & 0.440 & 0.034 & 0.864 \\
\hline
\end{tabular}

Normo-TG: TG, normotriglyceridemic patient subgroup, Hyper-TG: hypertriglyceridemic patient subgroup, b: coefficient, $p, p$ value. Other abbreviations as in Table 2.

and the TG level was not associated when assessed in the normotriglyceridemic patient subgroup.

Multivariate statistical analyses that took into account the values of BMI, systolic BP, and diastolic BP as well as the lipid and fibrinolytic parameters were also performed. Each coefficient value of BMI, systolic BP, and diastolic BP was between 0.1 and -0.1 in overall, hypertriglyceridemic, and normotriglyceridemic patients, suggesting that the RLP-C level was little influenced by these 3 parameters. Each $p$ value for these 3 parameters was more than 0.2 in each patient subgroup.

\section{Influence of diabetes mellitus}

RLP-C level may be influenced by the glucose level according to our multivariable analysis. Among the patients studied, 36 cases in group $\mathrm{S}$ and 11 cases in group $\mathrm{N}$ were diagnosed as having diabetes mellitus. Thus, we performed the second analysis among the subjects excluding these 47 diabetic patients (Table 7). In this additional analysis among the 161 non-diabetic patients analyzed, RLP-C showed a significant difference in the normotriglyceridemic subgroup but not in the hypertriglyceridemic subgroup.

\section{Effect of lipid lowering medicine}

Some drugs can affect lipoprotein profiles. Among the patients studied, 17 were taking statin, 8 were taking other lipid lowering medicine such as Niacin or Clofibrate, and 2 were taking both. Of these 27 patients, 20 were classified as group $\mathrm{S}$ and 7 were group $\mathrm{N}$. The ratio of subjects who were on these lipid lowering drugs showed no significant difference between groups $\mathrm{S}$ and $\mathrm{N}$. We performed the third analysis among the subjects excluding these 27 patients who were on the lipid lowering drugs. In this third analysis among the 181 patients ana- 
Table 7. Comparison of the Lipid Parameters between Non-diabetic Patients with (Group S) and Those without (Group N) Angiographically Determined Coronary Artery Stenosis

Panel A: Comparison assessed in the hypertriglyceridemic patient subgroup

\begin{tabular}{lccc}
\hline & Group S & Group N & $p$ Value \\
\hline TG (mg/dl) & $216.6 \pm 66.3$ & $168.5 \pm 63.6$ & 0.274 \\
RLP-C (mg/dl) & $9.20 \pm 5.45$ & $6.90 \pm 2.26$ & 0.457 \\
glucose (mg/dl) & $102.8 \pm 14.5$ & $91.0 \pm 11.1$ & 0.279 \\
\hline
\end{tabular}

Panel B: Comparison assessed in the normotriglyceridemic patient subgroup

\begin{tabular}{lccc}
\hline & Group S & Group N & $p$ Value \\
\hline TG $(\mathrm{mg} / \mathrm{dl})$ & $105.5 \pm 25.0$ & $98.1 \pm 30.4$ & 0.225 \\
RLP-C (mg/dl) & $5.48 \pm 4.81$ & $3.44 \pm 2.20$ & 0.021 \\
glucose (mg/dl) & $100.6 \pm 13.2$ & $93.2 \pm 11.4$ & 0.049 \\
\hline
\end{tabular}

Data presented are mean $\pm \mathrm{SD}$. Abbreviations as in Table 2.

lyzed, RLP-C also showed a significant difference in the normotriglyceridemic subgroup but not in the hypertriglyceridemic subgroup. Multivariate statistical analyses to assess the independent correlations between RLP-C level and levels of the other variables were also performed in these 181 patients. They showed the same tendency as the original ones; TG level was the only independent factor associated with RLP$C$ level when assessed in both overall patients and the hypertriglyceridemic patient subgroup but the levels of glucose and $L p(a)$ were independent factors associated with the RLP-C level, and the TG level was not associated when assessed in the normotriglyceridemic patient subgroup.

\section{Discussion}

Hypertriglyceridemia has been reported to be a powerful coronary risk factor when it coincides with a high LDL-C level $(17,18)$ or a low HDL-C level $(19)$. However, the association of neither LDL-C level nor HDL-C level with the presence of angiographically determined coronary artery stenosis showed different tendencies between hypertriglyceridemic and normotriglyceridemic patient subgroups in the present study. In contrast, a significant difference was observed in RLP-C level between groups $\mathrm{S}$ and $\mathrm{N}$ in the normotriglyceridemic patient subgroup whereas no difference in RLP-C level was found in the hypertriglyceridemic patient subgroup, suggesting that a higher level of RLP-C is associated with an increased risk for coronary artery stenosis predominantly in the normotriglyceridemic subjects.

VLDL secreted by the liver is not considered to be atherogenic in normal individuals (8). VLDL is hydrolyzed gradually into smaller particles by the action of LPL, and produces remnants which are subsequently converted to LDL by hepatic lipase. In the early studies of Gofman et al (20), VLDL remnants were suggested to be more atherogenic than LDL. It has been recently accepted that the levels of these TG-rich lipoprotein remnants may be as important as the LDL-C levels (21). But reports on the association between remnants of TG-rich lipoproteins and coronary artery disease are still limited, because the previous methods used to quantify TG-rich lipoprotein remnants were complex and did not lead to routine clinical use.

A simple and reliable method to measure the presence of remnant lipoproteins has been developed recently in Japan (9). This method uses an immunoaffinity gel mixture of anti apo B-100 and anti apo A-I monoclonal antibodies coupled to Sepharose 4B. A subpopulation of TG-rich particles is separated in the unbound fraction enriched in apo E. It was demonstrated that this subpopulation mainly consisted of chylomicron remnants and VLDL remnants (9). RLP-C is the level of this subpopulation quantified by the assay of cholesterol. A more detailed characterization has been given elsewhere (9). Although there are some reports on the levels of VLDL remnants or intermediate-density lipoproteins (IDL) in patients with coronary artery stenosis (22), reports on the levels of RLP-C in patients with coronary artery stenosis are few $(9,23)$. Associations of RLP-C levels with coronary events have recently been reported $(24,25)$. We have previously reported that RLP$\mathrm{C}$ levels are markedly high in patients who have established coronary artery stenosis (26). In the current study, we have demonstrated that the association of RLP-C level with the presence of coronary artery stenosis is high, especially in the normotriglyceridemic patients. A higher level of serum concentration of RLP-C appears to be a risk for the presence of coronary artery stenosis even when the serum TG level is not elevated. The present observations support for the first time 
the importance of the RLP-C assay as a possible means of isolating the patients with coronary artery stenosis from normotriglyceridemic subjects. To our knowledge, there have been no similar reports discussing IDL level nor VLDL remnant level.

In the current study, RLP-C was correlated with coronary artery stenosis in the normotriglyceridemic patient subgroup but not in the hypertriglyceridemic patient subgroup. It is unclear why there was no significant difference in the levels of RLP-C between groups $\mathrm{S}$ and $\mathrm{N}$ in the hypertriglyceridemic patient subgroup. RLP-C has been reported to be highly correlated with the plasma triglyceride level (9). In the hypertriglyceridemic patient subgroup, RLP-C levels were relatively high even in group $\mathrm{N}$, which is perhaps affected by higher TG levels (Table 4). In fact, both the TG level and RLP-C level in group $\mathrm{N}$ of the hypertriglyceridemic patient subgroup (Table 4) was higher than that in group $S$ of the normotriglyceridemic patient subgroup (Table 5). Thus, the association between the RLP-C level and coronary artery stenosis in the hypertriglyceridemic patient subgroup might be expected to underestimate the real effects of RLP-C. The negative results obtained here with regard to the association of the RLP-C level and coronary artery stenosis in the hypertriglyceridemic patient subgroup should not be taken to imply a lack of involvement in coronary atherosclerosis, but only an indeterminacy of the analysis.

The independent association of uric acid with coronary artery disease is less certain as compared with other conventional coronary risk factors (27). The existence of correlations between the uric acid level and lipid parameters or obesity results in an underestimation of the association between uric acid and coronary artery disease in multivariate analyses (27). Our observation that a higher level of uric acid is associated with coronary artery stenosis only in the hypertriglyceridemic patients is in line with previous reports.

A positive correlation between the TG level and PAI-1 level has been previously reported $(28,29)$. In the current study, the PAI-1 level tended to be higher in the hypertriglyceridemic patient subgroup than in the normotriglyceridemic patient subgroup but this difference did not reach a statistical significance (Table 3). The level of t-PA was significantly high in the hypertriglyceridemic patient subgroup. With regard to the difference of the association with coronary artery stenosis between hypertriglyceridemic and normotriglyceridemic patient subgroups, neither the t-PA level nor PAI-1 level showed different tendencies between the two subgroups (Tables 4 and 5). On the contrary, protein $\mathrm{C}$ showed a significant difference between groups $\mathrm{S}$ and $\mathrm{N}$ in the normotriglyceridemic patient subgroup but not in the hypertriglyceridemic patient subgroup. However, there are few reports concerning the protein $\mathrm{C}$ level and coronary artery stenosis (30). It remains undetermined whether the difference of the association of protein $\mathrm{C}$ with coronary artery stenosis between hypertriglyceridemic and normotriglyceridemic patient subgroups is meaningful or not. The current study was not able to answer this question.

With regard to the study limitations, this is an observational retrospective association study of a selected population of pa- tients. Thus, the findings will require confirmation in a prospective study. In conclusion, the current study found that RLP$\mathrm{C}$ levels are strongly associated with coronary artery stenosis, especially in patients with normal TG levels. The RLP-C assay may provide a possible means of differentiating the patients with coronary artery stenosis from among the normotriglyceridemic subjects.

Acknowledgements: We thank Mrs. Setsuko Masuoka for her helpful support in preparing the manuscript.

This work was supported in part by the Research Grant for Cardiovascular Diseases (11C-6) from the Ministry of Health and Welfare in Japan.

\section{References}

1) Grundy SM. Small LDL, atherogenic dyslipidemia, and the metabolic syndrome. Circulation 95: 1-4, 1997.

2) National Cholesterol Education Program Adult Treatment Panel II. Second Report of the Expert Panel on Detection, Evaluation, and Treatment of High Blood Cholesterol in Adults. Circulation 89: 1329-1446, 1994.

3) Castelli WP, Garrison RJ, Wilson PWF, Abbott RD, Kalousdian S, Kannel WB. Incidence of coronary heart disease and lipoprotein cholesterol levels: the Framingham study. JAMA 256: 2835-2838, 1986.

4) NIH Consensus Development Panel on Triglyceride, High-Density Lipoprotein, and Coronary Heart Disease. Triglyceride, high-density lipoprotein, and coronary heart disease. JAMA 269: 505-510, 1993.

5) Austin MA. Plasma triglyceride and coronary heart disease. Arterioscler Thromb 11: 2-14, 1991.

6) Brunzell JD, Schrott HG, Motulsky AG, Bierman EL. Myocardial infarction in familial forms of hypertriglyceridemia. Metabolism 25: 313-320, 1976.

7) Davignon J, Cohn JS. Triglycerides: a risk factor for coronary heart disease. Atherosclerosis 124 suppl: S57-S64, 1996.

8) Assmann G, Schulte H, von Eckardstein A. Hypertriglyceridemia and elevated lipoprotein(a) are risk factors for major coronary events in middleaged men. Am J Cardiol 77: 1179-1184, 1996.

9) Nakajima K, Saito T, Tamura A, et al. Cholesterol in remnant-like lipoproteins in human serum using monoclonal anti apo B-100 and anti apo A-I immunoaffinity mixed gels. Clin Chim Acta 223: 53-71, 1993.

10) Reiber JHC, Serruys PW, Kooijman CJ, et al. Assessment of short-, medium-, and long-term variations in arterial dimensions from computerassisted quantification of coronary cineangiograms. Circulation 71: 280$288,1985$.

11) Haase J, Di Mario C, Slager CJ, et al. In vivo validation of on-line and off-line geometric coronary measurements using insertion of stenosis phantoms in porcine coronary arteries. Cathet Cardiovasc Diagn 27: 1627, 1992.

12) Austen WG, Edwards JE, Frye RL, et al. A reporting system on patients evaluated for coronary artery disease. Report of the Ad Hoc Committee for Grading of Coronary Artery Disease, Council on Cardiovascular Surgery, American Heart Association. Circulation 51: 5-40, 1975.

13) Friedewald WT, Levy RI, Fredrickson DS. Estimation of the concentration of low-density lipoprotein cholesterol in plasma without use of the preparative ultracentrifuge. Clin Chem 18: 499-502, 1972.

14) Schmidt HHJ, Genschel JC, Wagner S, et al. Quantification of lipoprotein (a): comparison of an automated latex-enhanced nephelometric assay with an immunoenzymometric method. Eur J Clin Chem Clin Biochem 34: 119-124, 1996.

15) Ranby M, Nguyen G, Scarabin PV, et al. Immunoreactivity of tissue plasminogen activator and of its inhibitor complexes: Biochemical and multicenter validation of a two site immunosorbent assay. Thromb Haemost 61: 409-414, 1989.

16) Juhan-Vague I, Moerman B, De Cock F, et al. Plasma levels of a specific inhibitor of tissue-type plasminogen activator (and urokinase) in normal and pathological conditions. Thromb Res 33: 523-530, 1984. 


\section{MASUOKA et al}

17) Stampfer MJ, Krauss RM, Ma J. A prospective study of triglyceride level, low-density lipoprotein particle diameter, and risk of myocardial infarction. JAMA 276: 882-888, 1996.

18) Kameda K, Matsuzawa $Y$, Kubo M, et al. Increased frequency of lipoprotein disorders similar to type III hyperlipoproteinemia in survivors of myocardial infarction in Japan. Atherosclerosis 51: 241-249, 1984.

19) National Institutes of Health. Lipid Metabolism Disorders and Coronary Heart Disease. MMV Medizin Verlag GmbH, Munich, 1993: 141-160.

20) Gofman JW, Glazier F, Tamplin A, Strisower B, De Lalla O. Lipoproteins, coronary heart disease, and atherosclerosis. Physiol Rev 34: 589$607,1954$.

21) O'Keefe JH Jr, Lavie CJ Jr, McCallister BD. Insights into the pathogenesis and prevention of coronary artery disease. Mayo Clin Proc 70: 6979, 1995

22) Phillips NR, Waters D, Havel RJ. Plasma lipoproteins and progression of coronary artery disease evaluated by angiography and clinical events. Circulation 88: 2762-2770, 1993.

23) Sekihara $T$, Nakano $T$, Nakajima $K$. High postprandial plasma remnantlike particles-cholesterol in patients with coronary artery diseases on chronic maintenance hemodialysis. Jpn J Nephrol 38: 220-228, 1996.

24) Kugiyama K, Doi H, Takazoe K, et al. Remnant lipoprotein levels in fasting serum predict coronary events in patients with coronary artery disease. Circulation 99: 2858-2860, 1999.

25) Takeichi S, Yukawa N, Nakajima Y, et al. Association of plasma triglyceride-rich lipoprotein remnants with coronary atherosclerosis in cases of sudden cardiac death. Atherosclerosis 142: 309-315, 1999.

26) Masuoka $H$, Ishikura $K$, Kamei $S$, et al. Predictive value of remnant-like particles cholesterol/high-density lipoprotein cholesterol ratio as a new indicator of coronary artery disease. Am Heart J 136: 226-230, 1998.

27) Bonora E, Targher G, Zenere MB, et al. Relationship of uric acid concentration to cardiovascular risk factors in young men. Role of obesity and central fat distribution. The Verona Young Atherosclerosis Risk Factors Study. Int J Obes Relat Metab Disord 20: 975-980, 1996.

28) Mehta J, Mehta P, Lawson D. Plasma tissue plasminogen activator inhibitor levels in coronary artery disease: Correlation with age and serum triglyceride concentrations. J Am Coll Cardiol 9: 263-268, 1987.

29) ECAT angina pectoris study group. ECAT angina pectoris study: baseline associations of haemostatic factors with extent coronary arteriosclerosis and other coronary risk factors in 3000 patients with angina pectoris undergoing coronary angiography. Eur Heart J 14: 8-17, 1993.

30) Vigano S, Mannucci PM, D'Angelo A, et al. Protein $C$ antigen is not an acute phase reactant and is often high in ischemic heart disease and diabetes. Thromb Haemost 52: 263-266, 1984. 